\title{
Investigation of the Nodularisation Propensity of Calcined Cashew-Nut Shell-Ash in Cast-Iron Melt
}

\section{Graphite}

\author{
O. I. Sekunowo ${ }^{1 *}$, J. O. Ugboaja ${ }^{2}$, J. A. Tiamiyu ${ }^{1}$ \\ ${ }^{1}$ Department of Metallurgical and Materials Engineering, University of Lagos, Akoka, Nigeria. \\ ${ }^{2}$ Nigerian Metallurgical Development Centre, Jos, Nigeria.
}

ABSTRACT: Production of ductile iron using ferrosilicon-magnesium master alloy in melt treatment is currently fraught with challenges bothering on cost and availability. In this study the suitability of cashew nut shells ash (CNSA) as a viable alternative to magnesium master alloys employed in the treatment of molten cast iron for enhanced mechanical properties was studied. The carbonized CNSA used varied from 2-10 wt. \% to treat different heat batches; CA1-CA5 containing varied amount of CNSA, $\mathrm{CaO}$ and FeSi in the molten cast iron. The cast samples were subjected to both mechanical characterisation (tensile, hardness and impact) and microstructural analysis using Instron electromechanical machine, impact tester and scanning electron microscope (SEM) coupled with energy dispersive spectroscope (EDS). Results show that the $8 \mathrm{wt}$. \% CNSA addition demonstrated the best mechanical properties comparable to ASTM A536 ferritic ductile cast iron. Specifically, the 8 wt. \% CNSA cast samples exhibited $433 \mathrm{MPa}$ tensile strength, 144HRC hardness and ductility of 14.7\%. Contributions to improved mechanical properties may be attributed to the development of sufficient fractions of graphite nodules during melt treatment with CNSA. These outcomes are a boost both to the production of quality ductile irons and a cleaner environment.

KEYWORDS: Nodularisation, ductile-iron, cashew-nut, ferrosilicon-magnesium alloy, mechanical properties

[Received Dec. 4, 2019; Revised Nov. 13, 2020; Accepted Feb. 01, 2021]

Print ISSN: 0189-9546 | Online ISSN: 2437-2110

\section{INTRODUCTION}

Despite the huge development in the production of grey and malleable irons, the search for the ideal cast iron in an ascast condition that exhibit mechanical properties comparable or superior to malleable iron continues. It has been established that the issue revolves around the control of graphite shape to form spheroids instead of precipitating as flakes (Bravo et al., 2007; Tvarozek and Lickova, 2013; Covino-Villaz et al., 2019). However, this is not feasible unless those inherent impurities in the melt such as chromium, vanadium, sulfur, phosphorus and other oxides are effectively purified.

Treatment of cast iron melt with certain alloys induces a condition known to promote the presence of free carbon in form of spheroids or nodules. Magnesium, cerium, yttrium, calcium and some other chemically reactive metals have been found to be suitable for molten cast-iron de-oxidation treatment (Conejo and Hermandez, 2006; Bui et al., 2012). The treatment enables flake graphite in cast iron to transform to spheroids or nodules. Among these reactive metals, magnesium appears to be the most economical and also required in minute amount (Bahubali and Vasudev, 2013).

*Corresponding author: osekunowo@unilag.edu.ng
There are currently about 210 patented ways of adding modifiers to molten cast iron.

Generally, the morphology of graphite in cast iron influences the mechanical properties in particular the ductility. Thus, cast iron melt is usually treated using ferrosilicon-magnesium alloys to transform intrinsic graphite flakes into spheroids or nodules which are known to confer ductility on the cast product (Bahubali and Vasudey (2013); Hatung et al., 2014). This process of cast iron melt treatment using ferro-magnesium-silicon $(\mathrm{FeMgSi})$ alloy with the aim of converting intrinsic graphite flakes into spheroids or nodules is referred to as nodularisation. Hence, the molten iron that has been so treated using magnesium master alloy is called ductile iron (DI).

Magnesium sources mainly from its ore (including magnesite, dolomite and brucite among others) require either electrolytic or thermal reduction processes to obtain pure magnesium for industrial purposes. This approach is rather complex and also not cost competitive. It has been discovered however, that magnesium can be sourced alternatively from various agro-wastes thereby offering huge benefits with environmental issues mitigation in addition (Obi et al., 2016). Various agro industrial by-products and wastes have been studied with a view of using them as input in many industrial 
processes. Specifically, the foundry industry will benefit immensely from processed agro-wastes inform of additives in melt refining. Furthermore, the physicochemical state of molten cast iron melt changes during nodularisation as the microstructure is modified such that the number of nucleation sites available for the growth of graphite nodules is greatly increased. This invariably often translates to improved mechanical properties of ductile irons (DI) with optimum machinability (Borse and Mangulkar, 2014).

According to Ogundiran et al., (2011), cashew is one of leading cash crops in Nigeria which is the world's second largest producer. Currently, Nigeria produces 636,000 tons of cashew nuts annually with a steady increase of its production most of which is exported either as whole shell or processed. Cashew processing generates cashew nut shells as a waste product, a fraction of it is utilised as a source of heat for boilers (Jekayinfa and Omisakin, 2005). The perennial nature of the crop means an abundance of waste cashew nut shells at the peak of the season which are dumped openly and subsequently subjected to indiscriminate burning (Adeigbe $e t$ $a l$, 2015). However, it is established that cashew nut shells contain significant quantities of potassium, magnesium, calcium and trace amounts of copper, zinc and iron (Jekayinfa and Omisakin, 2005).

The above notwithstanding, industrial graphite nodularisation treatments, with magnesium as the base treatment agent, entails that due diligence is taken to avoid fire outbreak. This phenomenon is known as pyro-effect which can make the process violent and unsafe. It also causes significant magnesium $(\mathrm{Mg})$ losses due to burning and hence, reduction of residual $\mathrm{Mg}$ content in solidified castings. Magnesium losses also occur because of its reaction with other elements contained in liquid iron; primarily with sulphur and secondarily with oxygen (Olawale et al., 2016).

The current study is imperative given the rather exorbitant cost and near non-availability of magnesium ferrosilicon master alloy due to paucity of foreign exchange. This is currently impacting negatively on the cost of ductile iron (DI) in Nigeria. The aim of this study is to investigate the feasibility of extracting magnesium from cashew nut shell ash (CNSA) and determine its suitability as cast iron nodulariser.

\section{MATERIALS AND METHODS}

\section{A. Materials}

The materials used for this study include silica sand for moulding; bentonite clay and pulver-bond clay (facing powder clay) sourced at Nigerian Machine Tools (NMT) Oshogbo while steel scraps as the base metal were sourced from National Metallurgical Development Centre (NMDC), Jos alongside graphite coke of 72 wt. \% Carbon for carburization of the melt. The cashew nut (Figure 1a) and its shells (Figure 1b) was sourced from Abod Success Investment Ltd, Lagos, an agricultural produce processing firm; while the ferrosilicon master alloy of $70 \mathrm{wt}$. \% silicon used for melt inoculation and the calcium oxide (calcined lime) used for de-phosphorisation of the melt were sourced from NMDC, Jos. Furthermore, all consumables for metallographic analysis such as bakelite powder, alumina, cerium oxide, diamond paste, silicon carbide powder and polishing papers were also sourced from NMDC, Jos.

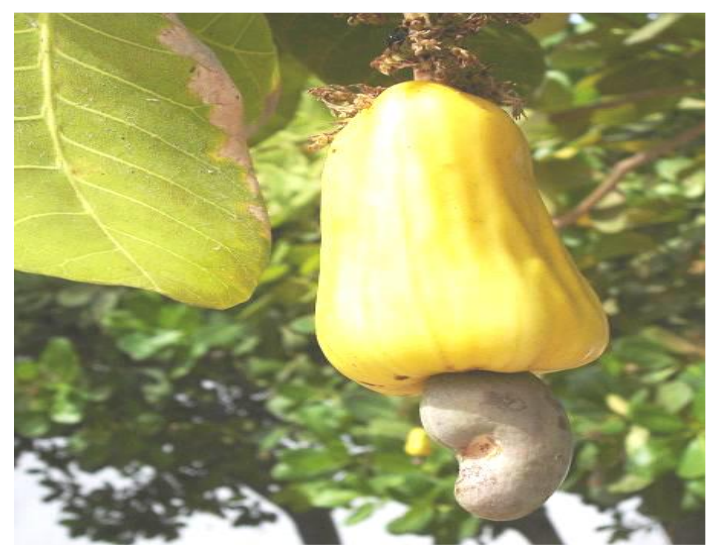

Figure 1a: Picture of Cashew fruit.

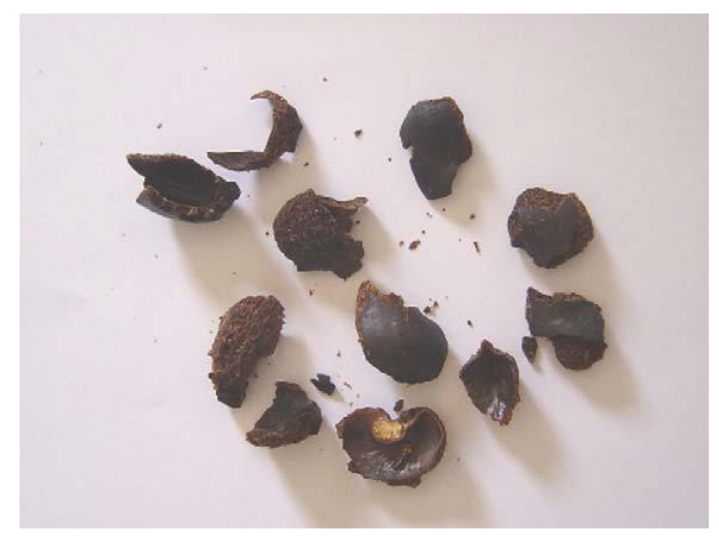

Figure 1b: Cashew nut shells.

\section{B. Methods}

1) Calcination and Pelletisation of Cashew nut shell Ash

Calcination of cashew nut shells was carried out at the workshop of NMDC Jos, Plateau State, Nigeria. To make the cashew nut shells amenable to ball milling without coagulation, they were oven dried at $250^{\circ} \mathrm{C}$ for $3 \mathrm{hrs}$. The oven dried shells were then milled in a ball mill for $36 \mathrm{hrs}$ and sieved using standard BSS sieve mesh (200-250) to obtain 80 $\mu \mathrm{m}$ particle sizes. This was followed by calcination at $800^{\circ} \mathrm{C}$ in an Electric Kiln model ST131, Stanton, United Kingdom (Figure 2a) for 5 hrs resulting in cashew nut shell ash (CNSA) presented in Figure 2b. Pelletisation of the CNSA particles was carried out using a $300 \mathrm{~kg} / \mathrm{h}$ Petru-Volosciuc granulator at a pressure between $137 \mathrm{MPa}$ and 206MPa. The pelletised samples were kept in a desiccator to maintain their physicochemical conditions for subsequent use during melt treatment. 


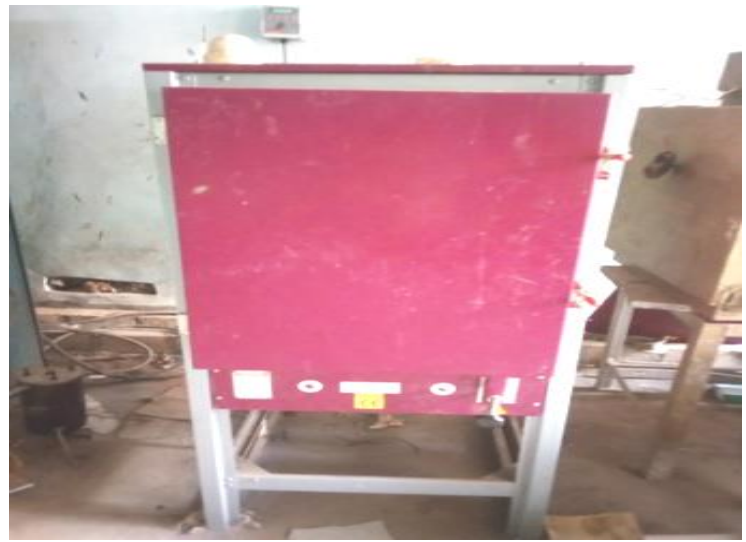

Figure 2a: Stanton electric kiln.

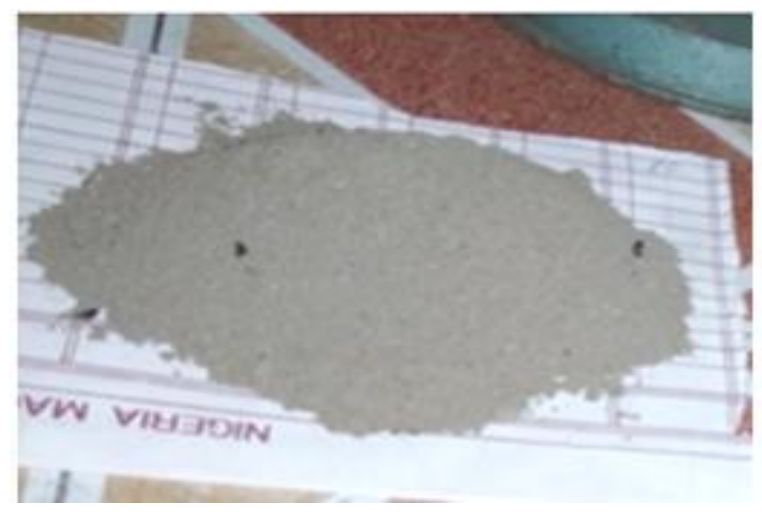

Figure 2b: Cashew nut shell ash; $80 \mu \mathrm{m}$.

\section{2) X-Ray Fluorescence Analysis on Cashew Nut Shell Ash}

Twenty grammes $(20 \mathrm{~g})$ of CNSA was oven dried at

$105^{\circ} \mathrm{C}$ for $1 \mathrm{hr}$ and cooled in open air. The ash was mixed with a binder in the ratio of $5 \mathrm{~g}$ CNSA to $1 \mathrm{~g}$ cellulose flakes. The cashew particles elemental concentrations was determined using an XRF, model ARL $9400 \mathrm{XP}^{+}$Thermo, Switzerland which was turned on to warm-up for $2 \mathrm{hrs}$. Shortly after, the appropriate energy band levels were selected and the average concentration of each element was obtained.

\section{3) Nodularisation procedure, melting and casting processes}

Melt treatment and casting was carried out at Oshogbo Machine Tools Foundry workshop in Osun State Nigerian. The utilisation of the prepared CNSA samples was carried out in a 2-ton capacity induction furnace facility. The procedure entailed batch addition of varied quantity of pelletised CNSA into the melt. Addition of the pelletised CNSA is meant to facilitate the transformation of substantial volume fraction of graphite in the melt to nodules instead of flakes. This procedure was repeated for varying wt. \%CNSA as highlighted below. The choice of CNSA addition regime in this study was informed by two factors namely; pyro-effect phenomenon and fading of magnesium during treatment. According to Huerta and Popovski (2005), cast iron graphite modifiers are required in minute amount to avoid pyro-effect phenomenon. However, this must be balanced up by adding sufficient amount of magnesium to compensate for losses during treatment (Hanus and Hanusova, 2012). CNSA samples were added in each mould labeled CA1 - CA5 with the following composition:

Mould CA1: 2 wt. \% CNSA in $4.3 \mathrm{~kg}$ liquid (86g CNSA), $50 \mathrm{~g}$ $\mathrm{CaO}$ and $12.9 \mathrm{~g} \mathrm{FeSi}$

Mould CA2: 4wt. \% CNSA (172g CNSA), 50g $\mathrm{CaO}$ and $12.9 \mathrm{~g} \mathrm{FeSi}$

Mould CA3: 6wt. \% CNSA (258g CNSA), 50g CaO and $12.9 \mathrm{~g} \mathrm{FeSi}$

Mould CA4: 8 wt. \% CNSA (344g CNSA), 50g CaO and 12.9g FeSi

Mould CA5: 10 wt. \% CNSA (430g), 50g CaO and 12.9g FeSi

Currently, there are about 210 patented methods of adding modifiers into molten cast iron. In-Mould treatment method was adopted for the melt nodularisation whereby the pouring ladle was preheated to $300^{\circ} \mathrm{C}$ by electric heater for about 40 $\mathrm{min}$. However, prior to the commencement of treatment, $2 \mathrm{wt}$. $\% \mathrm{CNSA}$ and $5 \mathrm{wt} . \% \mathrm{CaO}$ were placed at the mould pouring gate according to ASTM A 897 standard. Furthermore, the melt was inoculated using $0.3 \%$ FeSi followed by casting of the samples in sand moulds. The Y-block cast samples are shown in Figure 3.

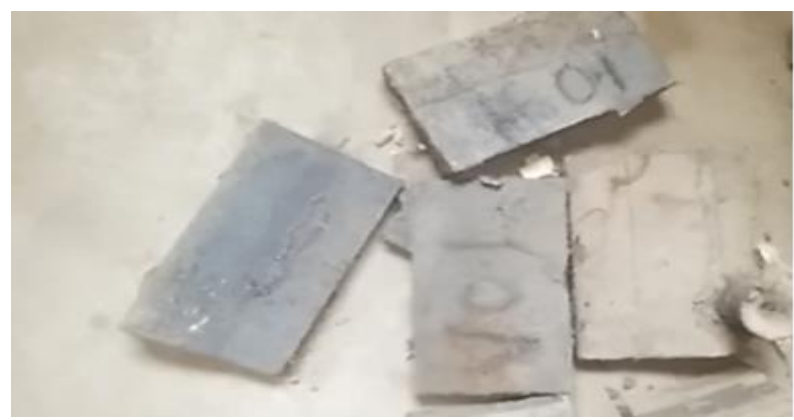

Figure 3: Y-Block samples.

\section{4) Mechanical characterisation}

Tensile test samples were mechanically cut and machined at room temperature according to ASTM E8-04 standard. The test was carried out using a computer controlled $100 \mathrm{kN}$ capacity Universal Mechanical Testing Machine model $3369 \mathrm{~K}$, Instron, USA, at a constant cross head speed of $1 \mathrm{~mm} / \mathrm{min}$. Yield and ultimate tensile stress as well as \% elongation was determined from the data generated during the test. Hardness test was conducted on good surface finish samples CA1-CA5 on a Rockwell hardness tester (Figure 4) model 4150AK, Indentec, UK with diamond cone indenter. Five measurements were taken at random on each sample. Furthermore, the impact energy of the cast samples was evaluated on V-notched Izod impact tester model 6705 manufactured by Avery-Denison, UK (Figure 5).

During each test cycle, a sample was mounted on the chuck of the machine, fastened on a vice and the V-notch was made to face upward at the center such that the hammer edge aligns with the V-notch. The dial pointer was turned to zero 
mark while the hammer was raised up to a height and then allowed on a free fall to hit the sample to fracture. The samples' impact energy absorbed in Joules was recorded.

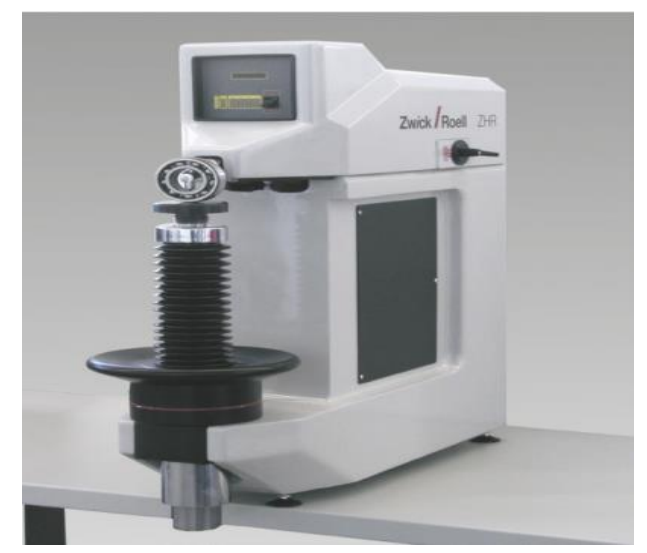

Figure 4: Picture of Rockwell hardness tester.

\section{5) Scanning Electron Microscope/Energy Dispersive Spectroscopy}

The cast samples microstructure and nodules induced were analysed according to ASTM E986-04 coupled with ASTM E 1508-12a (standard guide to quantitative analysis by EDS). The sample was placed in the electron gun chamber to obtain the images revealed by the computer controlled SEM/EDS machine, model EVO LS10 manufactured by Carl Zeiss, Germany.

\section{RESULTS AND DISCUSSION}

A. Composition of calcined cashew nut shell ash

The composition of cashew nut shells is as presented in Table 1 while the chemical composition of the cast samples is shown in Table 2.

On further analysis, the 13.03 wt. $\% \mathrm{MgO}$ approximates 8.3 wt. \% Mg. It was observed that elemental magnesium content in the cast samples increased marginally from $0.015-0.023 \mathrm{wt}$. $\%$ on the addition of CNSA from 2-8 wt. \%. The increase in elemental magnesium concentrations can be attributed to the intrinsic spontaneous reactivity of ferro-magnesium alloys. This level of magnesium is known to promote vigorous melt reaction and reduction in recovery (Hatung et al., 2014; Olawale et al.,

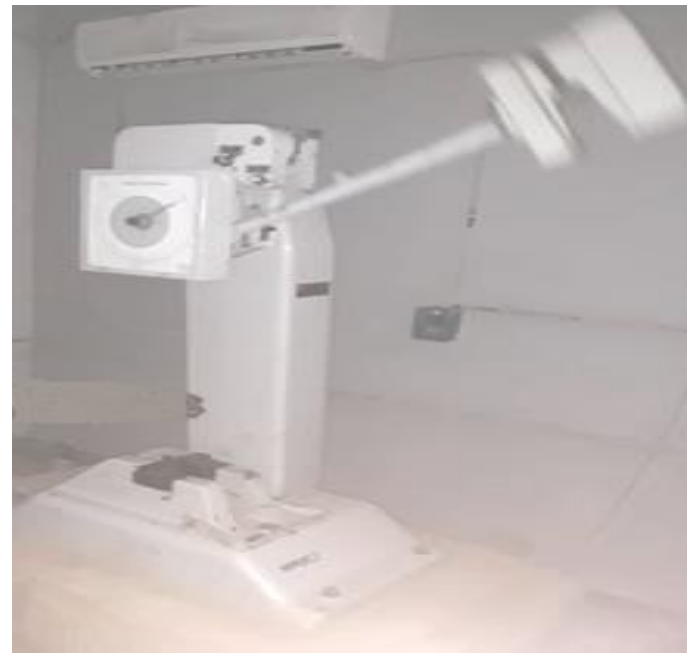

Figure 5: Avery impact energy tester.

2014). For example, high magnesium content, greater than 10 wt. \% often results in violent reactions and lower magnesium recovery due to the tendency to form oxides in open ladle treatment. However, a good balance must be attained between low magnesium treatment which causes poor nodularity and excess magnesium condition resulting in carbide formation (Hanus and Hanusova, 2012). It is observed that the samples 0.015-0.023 wt. \% Mg compared well with the standard specification of $0.014-0.025$ wt. $\% \mathrm{Mg}$ for ductile irons.

\section{B. Microstructure/Nodule Count}

Plates 1-3 show the SEM/EDS images of samples CA2, CA4 and CA5 respectively at 2, 8 and $10 \mathrm{wt}$ \% CNSA. Only a few nodules are seen in Plate 1 which may be due to impaired reactivity at a relatively low CNSA addition (Oluwole et al; 2007 Ecob and Hatung, 2012). However, the nodule count appears to increase as CNSA addition increases from 2-10 wt. $\%$ resulting in nodule count of $7-32 \%$. This observation can be explained as the direct effect of dissolved complex inclusions generated from slag. According to Marcin et al (2017), these inclusions may include $\mathrm{MgS}$ and $\mathrm{MgSO}$. The nodules are seen surrounded with vermicular graphite particles which suggest that they are compacted graphite

Table 1: X-Ray Fluorescence analysis result on cashew nut shell ash.

\begin{tabular}{lcccccccc}
\hline Oxide & $\mathrm{SiO}_{2}$ & $\mathrm{Al}_{2} \mathrm{O}_{3}$ & $\mathrm{~K}_{2} \mathrm{O}$ & $\mathrm{Fe}_{2} \mathrm{O}_{3}$ & $\mathrm{MgO}$ & $\mathrm{P}_{2} \mathrm{O}_{5}$ & $\mathrm{TiO}$ & L.O.I. $^{*}$ \\
\hline $\mathrm{Wt} / \%$ & 15.024 & 0.279 & 19.410 & 1.921 & 13.031 & 8.632 & 0.030 & 41.673 \\
\hline
\end{tabular}

Table 2: X-Ray Fluorescence analysis result of cast samples.

\begin{tabular}{ccccccc}
\hline Sample ID & \multicolumn{7}{c}{ Elements, wt. \% } \\
\cline { 2 - 6 } & $\mathrm{C}$ & $\mathrm{Si}$ & $\mathrm{Mn}$ & $\mathrm{P}$ & $\mathrm{S}$ & $\mathrm{Mg}$ \\
Control & 3.75 & 1.95 & 0.326 & 0.027 & 0.004 & 0.001 \\
CA1 & 3.63 & 2.22 & 0.252 & 0.005 & 0.005 & 0.015 \\
CA2 & 3.63 & 2.31 & 0.29 & 0.014 & 0.012 & 0.016 \\
CA3 & 3.74 & 2.42 & 0.25 & 0.015 & 0.012 & 0.019 \\
CA4 & 3.62 & 2.46 & 0.267 & 0.005 & 0.003 & 0.023 \\
CA5 & 3.82 & 2.25 & 0.282 & 0.034 & 0.013 & 0.018 \\
\hline
\end{tabular}




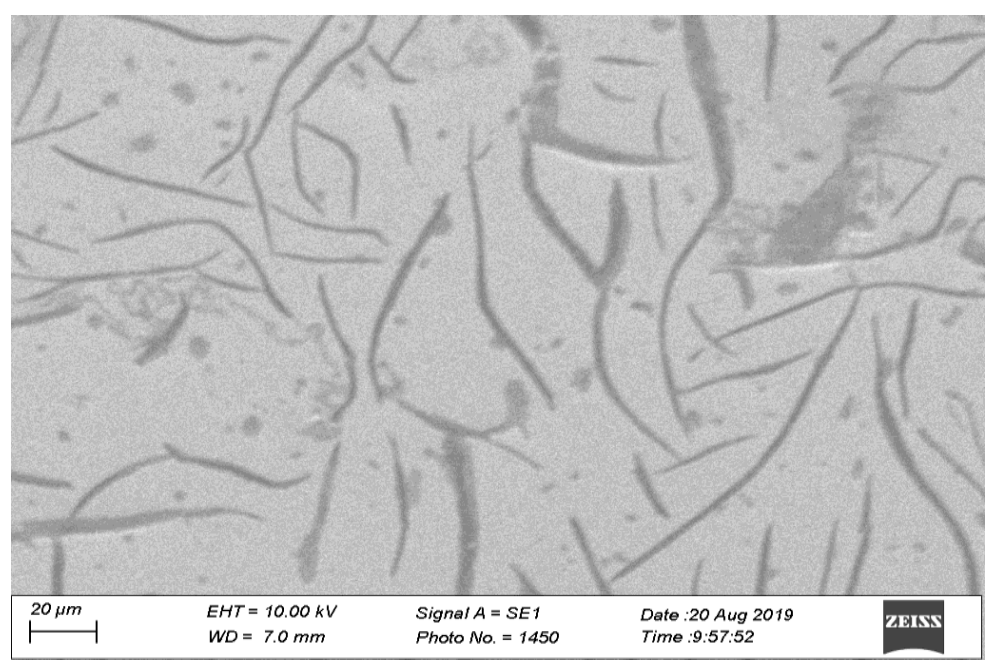

(a)

Plate 1: SEM/EDS (a) image (b) spectra of cast samples at 2 wt. \% CNSA.

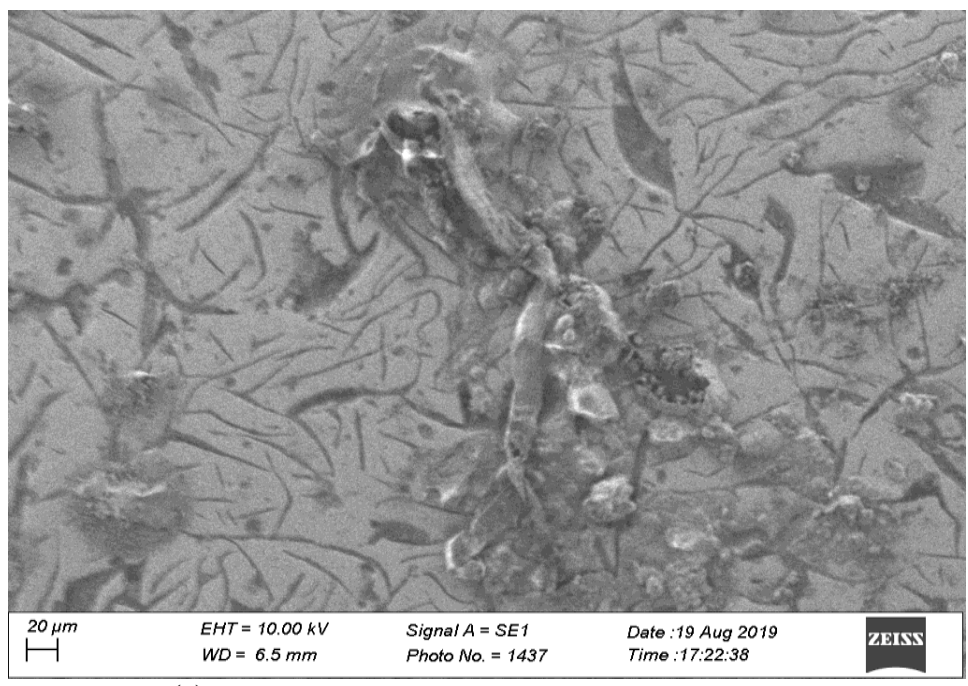

(a)

Plate 2: SEM/EDS (a) image (b) spectra of cast samples at 2 wt. \% CNSA.

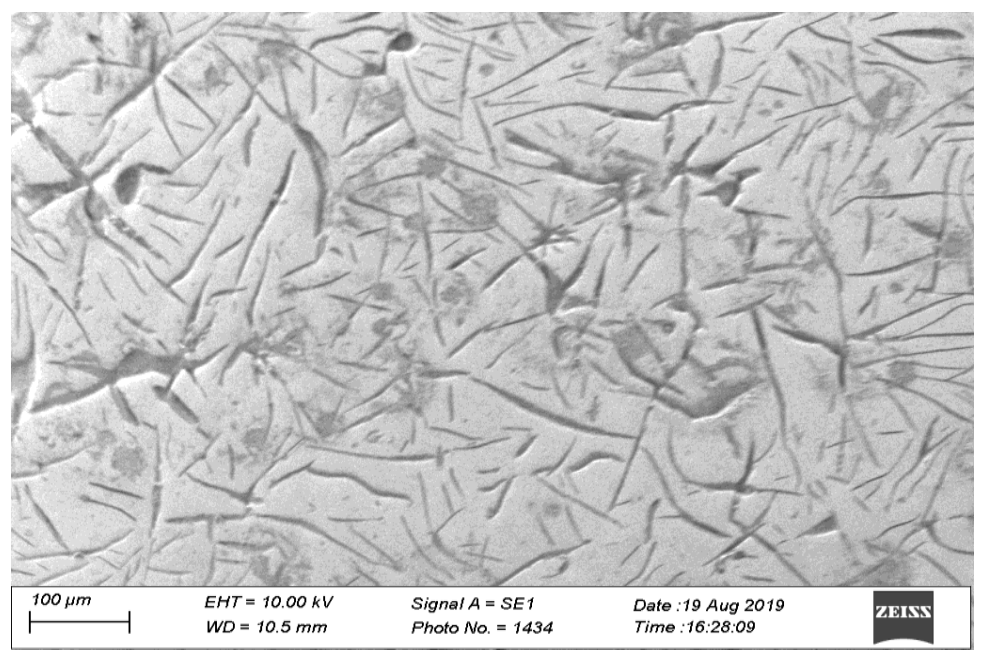

(a)

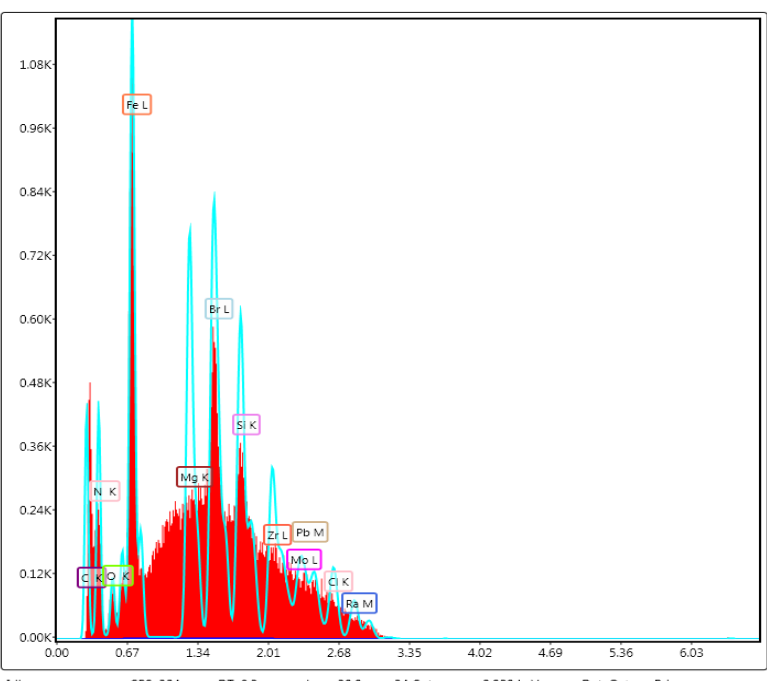

(b)

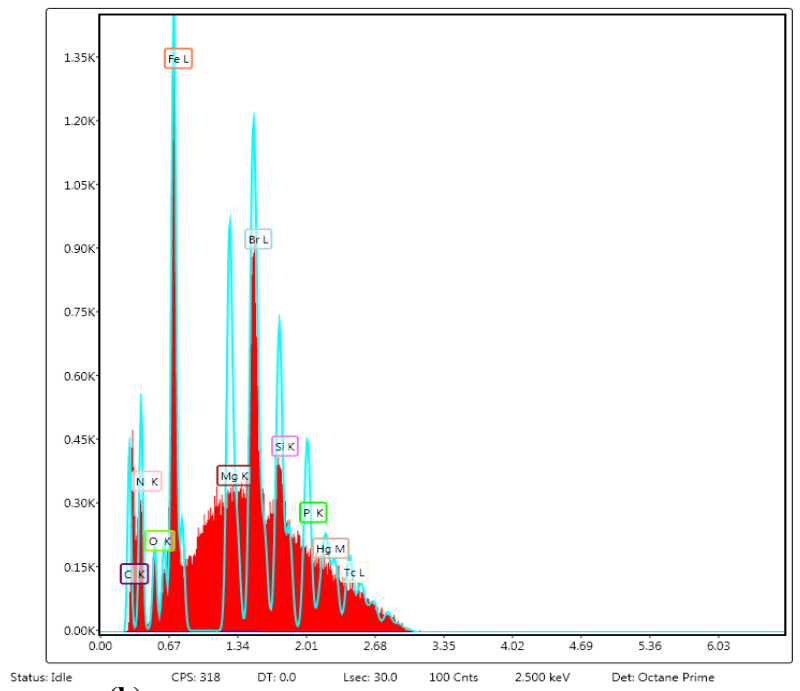

(b)

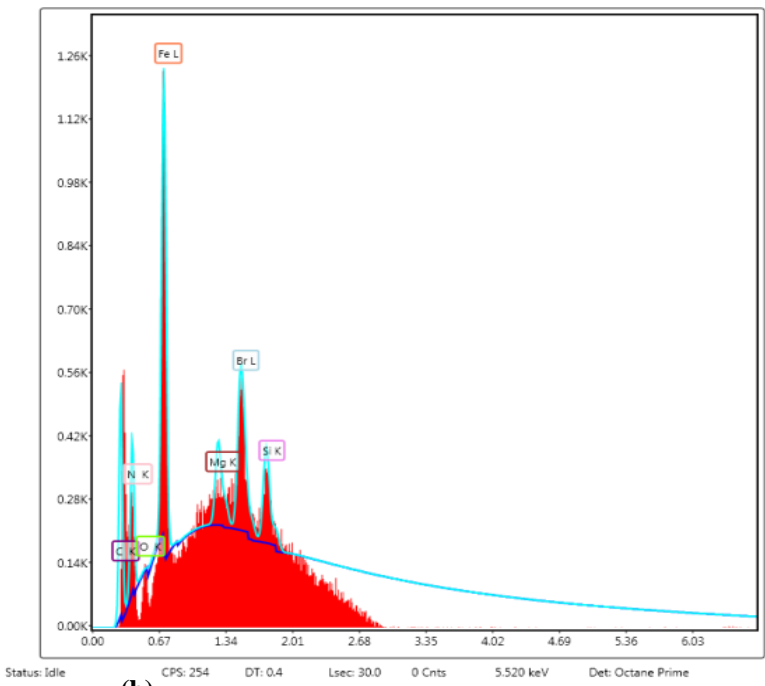

(b)

Plate 3: SEM/EDS (a) image (b) spectra of cast samples at 2 wt. \% CNSA. 
within ferrite matrix. This may be attributed to the section thickness which usually affects graphite nodule formation in an under-treated environment. According to Ecob and Hatung (2012), compacted nodules often occur in sections above 35 $\mathrm{mm}$ thickness. The thickness of the Y-block cast sample in this study is $50 \mathrm{~mm}$ giving rise to less than $35 \%$ nodularity whereas, under-treatment in thin section are reported to produce greater than $55 \%$ nodularity.

Furthermore, there was a combination of crab graphite presence in the micrographs. Crab graphite is an aggregate of graphite flakes formed probably due to segregation occurring in the thick-walled ductile iron. As the CNSA addition to the melt was increased to $8 \mathrm{wt}$. \%, the crab graphite structure reduced and the vermicular structure becomes more visible. The irregular shaped particles seen in the microstructure appears to be dissolved complex inclusions generated from slag. These inclusions may include $\mathrm{MgS}$ and $\mathrm{MgSO} 4$ being one of the effects of in-mould nodularisation treatment process (Marcin et al., 2017).

The cast samples ultimate tensile strength (UTS) at varied CNSA addition is illustrated in Figure 6. The UTS increases in response to increase in CNSA addition. This may be attributed to melt reactivity resulting in graphite nodules formation (Bahubali and Vasudev, 2013). Thus, the amount of matrix reinforcing nodules correlates the wt. \%CNSA addition reaching its peak at $8 \mathrm{wt} . \%$. Graphite nodules appear to provide significant resistance to dislocation motion within the relatively soft ferrite matrix (Al-Ghonamy et al., 2012; Wang et al., 2019) hence, the level of UTS; 391.2-433.1 MPa exhibited by the cast samples at varied CNSA addition. This performance level compares well with standard UTS specified for ductile iron (DI) used in tensile load bearing applications.

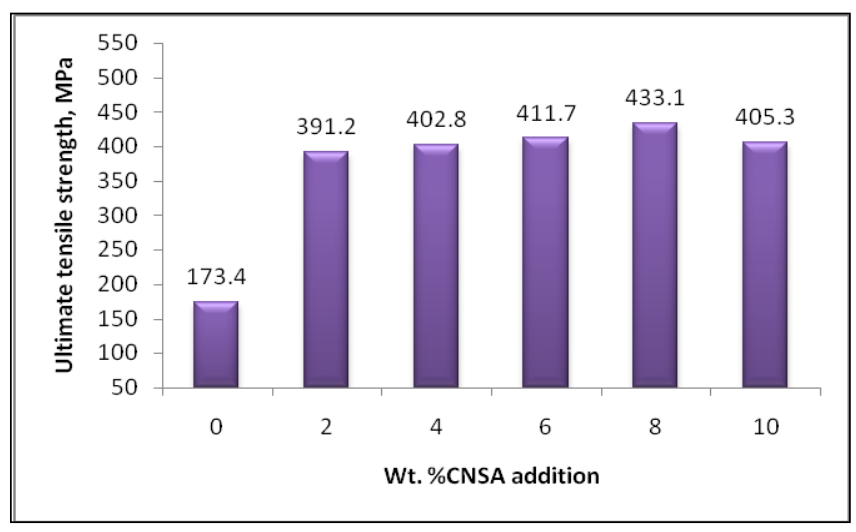

Figure 6: Effect of varied CNSA addition on tensile strength of cast iron.

\section{Ductility}

The ductility evaluated in term of $\%$ elongation of the cast samples at varied CNSA addition is presented in Figure 7. The sample without CNSA addition shows brittleness which is characteristic of conventional cast iron. This stemmed from the preponderance of the presence of graphite flakes in the microstructure. The morphology of graphite flakes shows sharp and pointed tips which are known to be points of stress concentration (Walter and Pilkey, 2007).

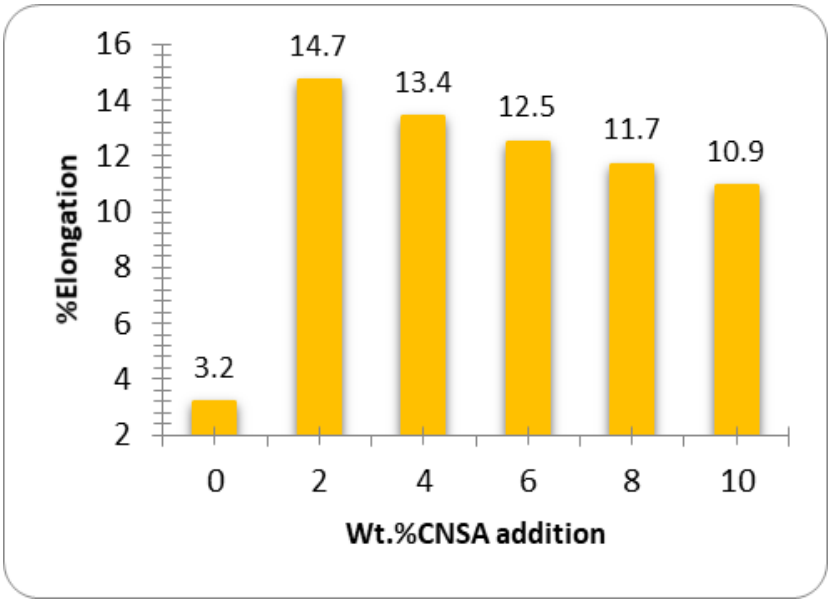

Figure 7: Effect of varied CNSA addition on\% elongation of cast iron.

Under external force, cracks are easily initiated at the point of stress concentration resulting in brittle failure. However, addition of varied wt. \% of CNSA to the melt gave rise to varied level of graphite nodules which significantly affect the cast samples ductility (Nakae and Shin, 2001; Wang et al., 2019). Aside the control sample, the level of ductility demonstrated by the samples is comparable to the $10 \%$ (minimum) acceptable standard usually confer by synthetic master alloy $(\mathrm{FeMgSi})$.

\section{E. Impact energy}

The behaviour of the cast samples under dynamic loading was assessed in term of impact energy absorption and the result is illustrated in Figure 8. The ability of the samples to resist failure under impact load increased with CNSA addition and culminated in $19.3 \mathrm{~J}$ at $8 \mathrm{wt}$. \%. Improvement in the impact toughness can be attributed to the nodular morphology which promotes inter-atomic cohesion coupled with the synergistic influence of each nodule within the matrix (Cocco and Iacoviello, 2015; Iacoviello et al., 2016). Thus, the types of microstructure developed in the samples were such that enhanced reasonable level of impact energy absorption before fracture (Nicoletto et al., 2006). This is sequel to increase in the amount of graphite nodules formed at varied wt. \% CNSA addition. However, the propensity of graphite nodules formation reduces beyond 8 wt. \% CNSA addition hence reduction in impact energy from $19.3 \mathrm{~J}$ to $16.1 \mathrm{~J}$.

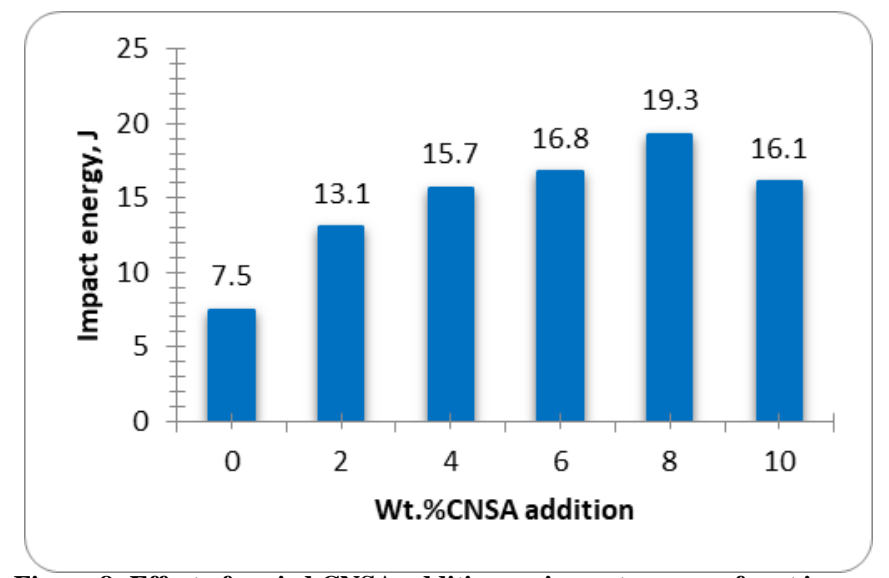

Figure 8: Effect of varied CNSA addition on impact energy of cast iron. 


\section{F. Hardness}

The hardness induced in the cast samples at varied nodularisation treatment is shown in Figure 9. Hardness increases marginally as the wt. \%CNSA addition increases. This can be attributed to the intrinsic hardness which is characteristic of cast iron (Vaskova et al., 2013). However, this behaviour appears to have been modified by the type of microstructure developed in the samples on addition of CNSA. (Souza et al., 2014). It is envisaged that the corresponding modest level of hardness conferred on the samples will be beneficial in curtailing the conventional cast irons wear rate in service (Hatate et al., 2001). Beyond 8 wt. $\%$ CNSA addition, it is observed that that the inter-atomic cohesion is impaired giving rise to a reduction in hardness from 144.5 HRC to 128.4 HRC representing a difference of 11. $1 \%$ compared with just 2 wt. $\%$ CNSA addition increase. This shows a significant influence of CNSA addition on the cast iron microstructure and the functional properties.

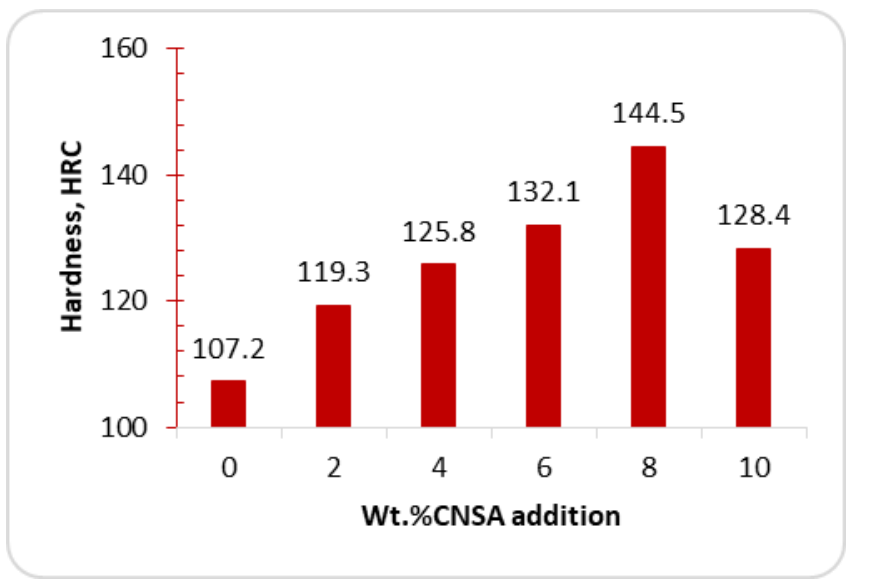

Figure 9: Effect of varied CNSA addition on hardness of ductile iron.

\section{CONCLUSION}

The study investigated the nodularisation propensity of calcined cashew nut shell ash (CNSA) in cast-iron melt graphite. From the results and their analyses, the following inferences were drawn:

1. The chemical composition shows that CNSA contains $0.014-0.025$ wt. $\% \mathrm{Mg}$ and this is sufficient for Nodularisation.

2. Graphite nodules developed in the cast samples are such that aid improved mechanical properties comparable to ductile irons (DI) produced using conventional FeMgSi master alloy.

3. Ductility demonstrated by cast samples in the range of 10.9-14.7 \%, is adjudged to be adequate considering the standard specification which is $10 \%$ minimum.

\section{REFERENCES}

Adeigbe, O.; F. Olasupo; B. Adewale; and A. Muyiwa. (2015). A Review on Cashew Research and Production in
Nigeria in the last Four Decades. Academic Journals, 10 (5): 196-209.

Al-Ghonamy, A.; M. Ramadan; N. Fathy; K. Hafaz; and A. El-Wakil. (2012). Effect of Graphite Nodularity on Mechanical Properties of Ductile Iron for Waterworks Fittings and Accessories. International Journal of Civil \& Environmental Engineering, 10 (3): 1-5.

Bahubali, B. and Vasudev, D. (2013). The Effect of Inoculation on Microstructure and Mechanical Properties of Ductile Iron. Journal of Mechanical and Civil Engineering, 5 (6): 17-23.

Borse, C. and Mangulkar, Y. (2014). Review of Grey Cast Iron Inoculation. International Journal of Innovative in Science, Engineering and Technology, 3 (4): 31-35.

Bui, A., T. Le; and B. Nguyen. (2012). Decarburisation of Molten Iron under Reduced Pressure. ASEAN Engineering Journal B, 3 (1): 55-61.

Bravo S.; K. Yamamoto; H. Miyahara; and K. Ogi. (2007). Control of Carbides and Graphite in Ni-Hard Type Cast Iron Hot Strip Mills. Materials Science Forum, 361: 1023-1026.

Cocco, V. and Iacoviello, F. (2015). Pearlitic Ductile Cast-Irons: Fatigue Initiation Micromechanics. Procedia Engineering, 109: 465-472.

Cofino-Villaz, A.; F. Alrarez-Antilus; J. Asesio.; and M. Garcia. (2019). Control over the Percentage, Shape and Size of the Graphite Particles in Martensitic White Castings Alloyed with $\mathrm{Cr}, \mathrm{Nb}$ and $\mathrm{Mg}$. Materials, 12: 185-193; https://doi.org/10.3390/ma1210185.

Conejo, A. and Hermandez, D. (2006). Optimisation of Aluminium De-oxidation Practice in the Ladle Furnace. Materials and Manufacturing Processes, 21 (8): 796-803.

Ecob, C. and Hartung, C. (2003). An Alternative Route for the Production of Compacted Graphite Iron. Elkem Foundry Production, 23: 7-23.

Hanus, A. and Hanusova, A. (2012). Continuous Modification of Cast Iron by FLOTRET Method. Archives of Foundry Engineering (VERSITA) 12 (1): 43-48.

Hartung, C.; D. White; K. Copi; M. Liptak; and R. Logan. (2014). The Continuing Evolution of $\mathrm{MgFeSi}$ Treatments for Ductile and CG Irons. International Journal of Metal Casting, 8 (2): 7-15.

Hatate, M.; T. Shiota; N. Takahashi; and K. Shimizu. (2001). Influence of Graphite Shape on Wear Characteristics of Austempered Cast Irons. Wear, 251: 885889.

Huerta, E. and Popovski, V. (2005). A study of HoldTime, Fade Effects and Microstructure in Ductile Iron. Proceedings of the American Foundry Society (AFS) cast iron inoculation conference, Schaumburg, Illinois, 44-54.

Iacoviello, F.; V. Cocco.; and M. Cavallini. (2016). Fatigue Crack Propagation and Overload Damaging Micromechanisms in a Ferritic-Pearlitic Ductile Cast Iron. Fatigue \& Fracture of Engineering Materials \& Structure, 39 (8): 999-1011.

Jekayinfa, S. O.; and O. S. Omisakin. (2005).Energy Potentials of Some Agricultural Wastes as Fuel Materials in Nigeria. Agricultural Engineering Ejournal, 7: 51-63. 
Marcin, S.; J. Krzystof.; and D. Malwina. (2017). Selected Phenomena of In-mould Nodularisation Process of Cast Iron that Influences the Quality of Cast Machine Parts. Journal of Processes, 68 (5): 2-9.

Nakae, H.; and H. Shin. (2001). Effect of Graphite Morphology on Tensile Properties of Flake Graphite Cast Iron. Materials Transactions, 42 (7): 1428-1434.

Nicoletto, G.; L. Collini.; R. Konecna.; and E. Riva. (2006). Analysis of Nodular Cast Iron Microstructure for Micromechanical Model Development. International Journal for Environmental Mechanics, hpps://doi.org/10.1111/j.1475.

Obi, F. O.; B. O. Ugwuishiwu.; and J. N. Nwakaire. (2018). Agricultural Waste Concept, Generation, Utilisation and Management. Nigerian Journal of Technology, 35 (4): 957-964.

Ogundiran, M.; J. Babayemi.; and C. Nzeribe. (2011). Application of Waste Cashew Nut Shell for the Control of $\mathrm{Pb}$ and $\mathrm{Cd}$ Mobility in Waste Battery Contaminated Soil. Pacific Journal of Science and Technology, 12 (2): 472-475.

Olawale, J. O.; K. M. Oluwasegun; D. Ezemenaka.; and S. Adisa. (2014). Production of Austempered Gray Iron (ADI) Using Forced Air Cooling. Materials Performance and Characterisation, 3 (1): 355-370.
Olawale, J. O.; S. A. Ibitoye.; and K. M. Oluwasegun. (2016). Processing Techniques and Production of Ductile Iron: A Review. International Journal of Scientific and Engineering Research, 9 (7): 397-416.

Souza, T.; R. Nogueira.; J. Franco.; M. Agullar.; and P. Cellin. (2014). Mechanical and Microstructural Characterisation of Nodular Cast Iron with Nobium Addition. Materials Research, 17 (5): 1167-1172.

Tvarozek, J.; and M. Lickova. (2013). Structural and Stress Conditions of Graphite Cast Irons after Intense Heating and Controlled Cooling. American International Journal of Contemporary Research, 3 (3): 49-67.

Vaskova, I.; P. Sebek.; and I. Mulik. (2013). Hardness of Ductile Cast Iron Castings and Control. Manufacturing Technology, 13 (1): 120-122.

Walter, D. and Pilkey, F. (2007). Peterson's Stress Concentration Factors. $3^{\text {rd }}$, John Wiley \& Sons, Inc., Hoboken, New Jersey, 214.

Wang, Z.; X. Zhang.; F. Xu; K. Oian; and K. Chen. (2019). Effect of Nodularity on Mechanical Properties and Fracture Ferritic Spheroidal Graphite Iron. China Foundry, 16: 386-392. 